\title{
Nurses' professional values on patient care provisions and decisions
}

\author{
Farhan Al Shammari ${ }^{1}$, Rizal Angelo N. Grande ${ }^{* 1}$, Daisy A. Vicencio ${ }^{1}$, Saud Al Mutairi ${ }^{2}$ \\ ${ }^{1}$ College of Nursing, University of Hail, Hail, Kingdom of Saudi Arabia \\ ${ }^{2}$ Training and Scholarship Directorate, Ministry of Health, Riyadh, Kingdom of Saudi Arabia
}

Received: February 18, 2017

DOI: $10.5430 /$ jnep.v7n9p78
Accepted: April 4, 2017

URL: https://doi.org/10.5430/jnep.v7n9p78

\begin{abstract}
Objective: To determine the relationship of professional value system of nurses to their duties and functions specifically on patient care provisions and decisions among selected government hospitals in Hail city, Kingdom of Saudi Arabia.

Methods: The study utilized a Descriptive Correlational method of research inquiry where a 26-item questionnaire on nurse professional value system (NPVSR) were distributed to 150 staff nurses employed in 3 government hospitals in the City of Hail after which, their responses were correlated using Pearson $r$ against their demographic profiles such as gender, age, religion, ethnicity, educational attainment, years of practice, current unit or ward assignment and current rank or position.

Results: Based on the responses of the 150 participants, the results showed that there was no significant relationship that exists between their demographic profiles to their value systems on different patient care provisions and decisions during their clinical duties and employment as staff nurses.

Conclusions: The study implicated that the value systems of the participants are not dependent or influenced largely or directly by their gender, age, religion, ethnicity, years of practice, educational attainment, current ward or unit assignment and current rank or position. The data further revealed that for this specific group of participants, their professional value system may in some other ways influenced by other factors not mentioned or included in their demographic profiles for the study.
\end{abstract}

Key Words: Nurse professional values, Ethical care provision, Ethical care decision

\section{INTRODUCTION}

A nurse's actions reflect the ideals of the entire nursing profession, primarily encompassing the values of caring, compassion, and love for both sick and healthy patients (sometimes called clients). ${ }^{[1]}$ The origins of modern nursing profession are often attributed to Florence Nightingale, a British citizen who was born in Florence, Italy. Starting in the Crimean War (1853-1856), she selflessly devoted her life to caring for, and healing, wounded British soldiers and others. ${ }^{[2]}$ Nightingale is ascribed as the first nurse researcher and the pioneer of nursing research when she conducted a study describing the conditions of the British soldiers during the Crimean war. She is also a statistician, a social reformer and a nursing philosopher. ${ }^{[2-4]}$

To commemorate her legacy, many nursing students recite the Nightingale Pledge during their capping and pinning ceremonies as they enter the field of caring and accept the obligation to devote themselves to their chosen profession. ${ }^{[5]}$ These words symbolize the devotion of nurses to their profession and represent a promise that no matter what it takes,

*Correspondence: Rizal Angelo N. Grande; Email: grian0520@ gmail.com; Address: College of Nursing, University of Hail, Hail, Kingdom of Saudi Arabia. 
the nurse will protect the rights of the patients and advocate on their behalf. ${ }^{[5]}$

To realize this promise, nurses are accountable for their actions in the development and finalization of their clinical decisions and in the care that they provide. ${ }^{[6]}$ Although individuals cannot always determine whether their actions or decisions are ethical, Carvalho, Reeves, and Orford (2012) maintain that whatever we do in life, whether personal or work related, our behaviors are always based on reasons. ${ }^{[7]}$

Thompson (2014) stated that ethics refers to the spirit of community and is the collective belief and value system of any moral community or social and professional group. As members of a professional group, nurses are mandated to discharge their duties according to a code of ethics that prescribes acceptable behavior and decisions that are ethically sound and morally correct. ${ }^{[8]}$ When nurses provide care to their patients, the code of ethics for nurses guides their assessments of situations in which moral conflicts arise and helps them to determine the ethically and morally appropriate courses of action. ${ }^{[9]}$

Ethical decisions based on personal value systems differ from one individual to the next, as each person experiences a unique upbringing with exposure to various internal and external factors. ${ }^{[10]}$ Thus, as with all individuals, nurses' childhood influences affect the development of their innate value systems and the ways in which they appraise behaviors, actions, and situations, which makes the ethical decisionmaking of nurses diverse and personally variable. ${ }^{[11]}$

To understand how nurses arrive at decisions and discharge their functions during the provision of care, a publicly available standard of care should be followed at all times. Thus, this study used the Nurse Professional Values Scale-Revised (NPVS-R) to determine whether the professional values of nurses were related to their personal profiles as well as their unique cultural, familial, academic, and environmental identities. $^{[12]}$

The primary purpose of this study was to determine: (a) the profiles of the participants in terms of gender, age, ethnicity, highest educational attainment, years in practice as a nurse, current ward or unit assignment in the hospital, and current rank or position in the hospital; and (b) the extent to which the participants' profiles were related to their professional value system in their nursing care decisions and the provision of nursing care. To answer the second question, the 26 value statements of the NPVS-R were correlated with the participants' profiles.

Several previous studies have focused on the value systems of both professional and student nurses, but the present study

Published by Sciedu Press emphasizes a multicultural perspective, as the participants were drawn from an ethnically and geographically diverse nursing staff. ${ }^{[12-15]}$ The participants in this study reported being from the Middle East (either Saudi nationals or from other Middle Eastern countries), Asia (with a great number from the Indian Peninsula and Southeast Asia, including the Philippines and Indonesia), Latin America, North America, and Africa. This diversity of nurse participants enabled this study to be a platform for multicultural ideas about care, talents, and abilities in providing nursing care and formulating ethical decisions based on the innate and enduring values of each individual and fused to create competent nursing care. In addition to the staff diversity, the patients for whom they care are also diverse, as Saudi Arabia is home to millions of expatriates from the surrounding countries and continents. ${ }^{[16]}$

\section{Methods}

This quantitative, descriptive, correlational study was conducted from August to October 2016 among staff nurses at selected government hospitals in Hail City, Kingdom of Saudi Arabia. The study comprised 150 staff nurses from different wards and units of King Khalid Hospital, Hail General Hospital, and the Maternity and Children's Hospital in Hail City. The main survey instrument for the study was the NPVS-R, a 26-item questionnaire created by Drs Darlene Weis and Mary Jane Schank, distinguished professors in the College of Nursing, Marquette University, Milwaukee, WI, USA. ${ }^{[12]}$

The 26 items on the NPVS-R use a Likert-scale response format ranging from 1 (not important) to 5 (most important). Each item concerns a specific code provision and its interpretive commentary. All the items are phrased in the positive direction, and none is reverse scored. The total score is obtained by summing the numeric responses for each item, with the possible range of scores being 26-130. The higher the score, the stronger is a nurse's professional value orientation. The NPVS-R does not have subscales (Weis \& Shank, 2009). ${ }^{[12]}$

The instrument was developed by Drs Darlene Weis and Mary Jane Schank of Marquette University. In the study "Development and Psychometric Evaluation of the Nurses Professional Values Scale-Revised" published in the Journal of Nursing Measurement, the authors argued that the NPVS$\mathrm{R}$ scale was conceptualized based from the provisions of the American Nurses Association (ANA) Code of Ethics. ${ }^{[12]}$ In the article, the authors illustrated and made emphasis of the actions that are reflective of nurses' values and moral dispositions with regards to the provision of nursing care to patients. ${ }^{[12]}$ Nursing as a profession is devoted to promote optimum care to patients. When at a certain stage that 
the patient cannot sustain life, nurses are prepared and well trained to allow the patient's peaceful transition to death while preserving the dignity of the patient and the family. ${ }^{[17]}$ Throughout all these events in the practice, the ethical and moral courage of nurses are being tested. To this end, the tool provides an avenue for the evaluation of ethical competence and for nurses examine their thoughts, feelings and actions if it is ethical or not, will benefit the patients or will further harm them and will it be for the common good or only for one party or person. ${ }^{[18]}$

The revised form of NPVS resulted to five factors which are Caring, Activism, Trust, Professionalism and Justice. It has to be mentioned that the non-revised form of the NPVSR has eight factors compared to the revised form which has five. The factors included in the present form of the NPVS-R emphasizes in more broader form the factor of Caring, that has the most variance among the professional values, followed by Justice, which is the basis for all interface between professionals in all settings of care provisions. The other provisions are duty and loyalty and are reflected by the factor professionalism and trust. For the factors Activism encapsulates the provisions of the Nurses' Code of Ethics on the social nature of the profession and its accountability to the public being served. ${ }^{[19]}$

Particularly the City of Hail, the capital of the Hail province in the Northern Region, there are six hospitals, private and public combined and four of the hospitals are government owned. These are the Hail General Hospital, the King Khalid Hospital, the Maternity \& Children's Hospital, and the Mental Hospital of Hail, and they are directly managed and supervised by the Kingdom's Ministry of Health. The ministry provides a $100 \%$ subsidy to these government hospitals, including supplies, personnel salaries, and the construction of, and improvements to, the physical facilities, among other things. ${ }^{[16]}$ The participants for this study were drawn from the first three government hospitals; none was taken from the Mental Hospital of Hail. These three government-supervised hospitals provide health-care services for different types of health problems and have their own assigned centers. The Hail General Hospital is considered to be the oldest of the three, as it was established in 1957, and it is categorized as a tertiary general hospital with a separate convalescent unit within the hospital compound. The King Khalid Hospital is the largest of the three hospitals, and it is the only hospital in the Hail Region that is accredited by the Joint Commission International. It is a specialized hospital for trauma patients. The third hospital is the Maternity \& Children's Hospital, and as the name implies, it specializes in maternal and childhood-related health concerns and disorders, but it also provides treatment for other minor health problems. ${ }^{[20]}$
To yield a statistically valid result, the population was determined to get the total number of samples. Using stratified random sampling, representative samples were taken from all the hospital units and departments, which enabled us to cover the entire hospital staff. We distributed 80 questionnaires to each hospital, and 50 questionnaires were returned, which was enough to cover all the areas of the nursing department. We also used convenience sampling, whereby only the nurses who were present in the units and wards during the data collection visits were sampled.

When the number of nurses was finalized and approval was obtained, we distributed the questionnaires with profile sheets that solicited demographic information from the participants, including gender, age in years, religion, ethnicity, educational attainment, years in practice (in the current hospital), current ward or unit assignment, and current rank or position. We correlated the data from the demographic profiles with the participants' responses on the NPVS-R to determine whether their professional values reflected their patient care decisions in the discharge of their clinical duties. Specifically, the demographic variables were measured as follows: gender, either male or female; age in years, categorized as 20-30, 31-40, 41-50, and 51 and over; religion, categorized as Islam, Roman Catholicism, Hinduism, Buddhism, Orthodox, and others (not affiliated with the primary categories); ethnicity, categorized as Middle Eastern (subcategorized as Saudi National or Non-Saudi National), Asian and Pacific Islanders (citizens of Asian and Pacific Island countries such as India, Pakistan, Philippines, Vanuatu, and Fiji), North American (citizens of countries such as USA, Canada, and Mexico), Latino and Hispanic (citizens of South American or Caribbean countries), African (citizens of the countries in the African continent) and Others (which referred to those whose ethnicity or citizenship could not be assigned to any of the previous categories, such as people from Australia, New Zealand, European countries, and others). The response categories for years of practice were: less than 1 year (those employed from 1 day to 364 days), 1 to 3 years, 4 to 6 years, 7 to 10 years, and more than 10 years. The categories for current ward or unit assignment were: Medical, Surgical, Intensive Care Unit (e.g., Neonatal ICU, Medical ICU), Pediatrics, Obstetric, or Maternity Unit, Operating Room, Emergency Room, Outpatient Department, Training Office, Nursing Office, and Multiple Assignments (those who had more than one ward or unit assignment). The participants' current rank or position was categorized as Nurse 1 to 7, a supervisory position, a managerial position, a head nurse, or multiple positions or ranks.

To obtain a representative sample from each hospital unit or ward, we used stratified random cluster sampling. This 
sampling technique is used when a researcher wants to minimize extremes in the sample, because it ensures that all strata of the population are represented. To be sure that the hospitals' units and wards would be represented fairly, we determined the number of nurses in each ward or unit and computed the number of participants that we needed for the study. The inclusion criteria for nurses employed in the previously mentioned government hospitals were: (a) that they were employed officially during the period when the study was conducted, (b) that they were registered nurses in the Saudi Health Council, (c) that they had proof of assignment in a particular hospital ward or unit for a particular period, and (d) that they were able to understand the language in the NVPS-R, which is written in English. None of the nurses was excluded based on age, gender, ethnicity, or any of the other demographic variables used in this study.

We used SPSS (the Statistical Package for Social Sciences, licensed version for Windows 11.5 SPSS 16) to compute the degree of relationship between the participants' demographic profiles and their responses on the NVPS-R. First, we examined the data to determine which of the 26 items the participants perceived as either not important, important, very important, or most important in the practice of their profession as nurses, especially when they were actually providing care and making clinical decisions. Thus, we focused on responses that were based on the nurses' actual experiences in the different hospital wards and units with which they were affiliated. In addition, these experiences in the provision of nursing care reflected their most important judgments and decisions, augmented by their knowledge of particular clinical situations in which their ethical decision-making skills were tested.

\section{RESUlts}

Of the 150 participants in this study, 99\% were female, $60 \%$ were aged 20-30 years, 36.67\% were Muslim, and $38.67 \%$ were Roman Catholic (a slight difference of 1\%-2\%). With respect to ethnicity, 52\% were Asian or Pacific Islanders, $22.67 \%$ were Middle Eastern Saudi Nationals, and 20\% were Non-Saudi Nationals. Sixty percent of the participants had a Bachelor of Science in Nursing, 36\% had a diploma, 4\% had a master's degree, and none of the participants had a doctoral degree. Twenty-eight percent of the participants had 4-6 years of practice, and 23\% had 7-10 years. Nurses assigned to ICUs accounted for $21.33 \%$ of the participants, whereas OB/Maternity Ward nurses and those with multiple assignments each composed $16.67 \%$ of the participants. Lastly, for current rank or position, most of the participants $(54.67 \%)$ were Nurse $1 \mathrm{~s}$, followed by Nurse 2s $(9.33 \%)$ (see Table 1).

\section{Discussion}

Providing care to a diverse group of patients is a challenge for nurses, because it means that health care must be unique and individualized. In this regard, the ultimate guide for nursing care should be the Nursing Code of Ethics. ${ }^{[21]}$

In this study, we used the NPVS-R, which is based on the American Nurses Association Code of Ethics. The professional code enables society to demand practitioner accountability. ${ }^{[21]}$ The code provides clarity concerning the domain of professional nursing actions, the quality of professional care, patient safety, and the norms of the profession, and these values are crucial to professional practice and essential for developing and sustaining a professional identity. ${ }^{[19,22]}$

Some previous studies have used the NPVS-R as the primary tool in their inquiries, and some of them have been translated into Turkish and Chinese. In a study of Taiwanese professional nurses titled A Chinese version of the Revised Nurses Professional Values Scale: Reliability and Validity Assessment, Lin and Wang (2009) found an overall Cronbach's alpha coefficient of $0.90 .{ }^{[13]}$ Other studies that have used the NPVS-R include The Effect of Personal Values on Individuals' Ethical Behavioural Intentions: Evidence from Professional Auditors in People's Republic of China ${ }^{[14]}$ and Development and testing of an instrument to measure protective nursing advocacy. ${ }^{[15]}$

The use of the NPVS-R in various studies has made it more valid and reliable for future researchers. In the present study, for the 26 items in which each item presented a clinical scenario requiring a patient care decision, the choices on the response scale included not important (NI), somewhat important (SI), important (I), very important (VI), and most important (MI). ${ }^{[12]}$

Most of the participants rated items 16, 9, 15, 21, and 3 to be MI, whereas items 5, 4, 1, 17, and 19 were frequently rated as NI.

\section{Conclusion}

The primary finding of this study was the absence of a significant relationship between the participants' demographic profiles and their responses on the 26-item NSVP-R. Thus, based on the data from this study, we conclude that a person's set of professional values is not determined by his or her gender, ethnicity, years in practice at a particular workplace, rank or position, educational attainment, assignment to a particular unit or department, or age. ${ }^{[23]}$ Therefore, the influences on one's behavior or set of professional values might be innate. 
Table 1. Distribution of participants based on demographic profile

\begin{tabular}{|c|c|c|c|}
\hline Profile & & Frequency Distribution & Percentage Distribution (\%) \\
\hline \multirow{3}{*}{ Gender } & Female & 2 & 1.25 \\
\hline & Male & 148 & 98.75 \\
\hline & TOTAL & 150 & 100.00 \\
\hline \multirow{5}{*}{ Age in years } & $20-30$ & 97 & 64.67 \\
\hline & $31-40$ & 30 & 20.00 \\
\hline & $41-50$ & 16 & 10.67 \\
\hline & 51-up & 7 & 4.67 \\
\hline & TOTAL & 150 & 100.00 \\
\hline \multirow{7}{*}{ Religion } & Islam & 55 & 36.67 \\
\hline & Roman Catholic & 58 & 38.67 \\
\hline & Hindu & 12 & 8.00 \\
\hline & Buddhist & 0 & 0.00 \\
\hline & Orthodox & 8 & 5.33 \\
\hline & Others & 17 & 11.33 \\
\hline & TOTAL & 150 & 100.00 \\
\hline \multirow{8}{*}{ Ethnicity } & Middle Eastern (Saudi National) & 34 & 22.67 \\
\hline & Middle Eastern (Non-Saudi) & 30 & 20.00 \\
\hline & Asian/Pacific Islander & 78 & 52.00 \\
\hline & North American & 1 & 0.67 \\
\hline & Latino/Hispanic & 1 & 0.67 \\
\hline & African & 6 & 4.00 \\
\hline & Others & 0 & 0 \\
\hline & TOTAL & 150 & 100.00 \\
\hline \multirow{5}{*}{ Educational Attainment } & Diploma & 54 & 36.00 \\
\hline & Bachelor & 90 & 60.00 \\
\hline & Masters & 6 & 4.00 \\
\hline & Doctorate & 0 & 0.00 \\
\hline & Total & 150 & 100.00 \\
\hline \multirow{6}{*}{$\begin{array}{l}\text { Year/s of Practice } \\
\text { (in the current hospital) }\end{array}$} & Less than 1 & 26 & 17.33 \\
\hline & $1-3$ & 23 & 15.33 \\
\hline & $4-6$ & 42 & 28.00 \\
\hline & $7-10$ & 35 & 23.33 \\
\hline & 10 and above & 24 & 16.00 \\
\hline & TOTAL & 150 & 100.00 \\
\hline \multirow{13}{*}{ Current Ward/Unit Assignment } & Medical & 15 & 10.00 \\
\hline & Surgical & 7 & 4.67 \\
\hline & ICU & 32 & 21.33 \\
\hline & Pediatrics & 13 & 8.67 \\
\hline & OB/Maternity & 25 & 16.67 \\
\hline & Operating Room & 7 & 4.67 \\
\hline & Recovery Room & 1 & 0.67 \\
\hline & Emergency Room & 10 & 6.67 \\
\hline & Out-Patient Dept. & 2 & 1.33 \\
\hline & Training Office & 3 & 2.00 \\
\hline & Nursing Office & 10 & 6.67 \\
\hline & Multiple Assignment & 25 & 16.67 \\
\hline & TOTAL & 150 & 100.00 \\
\hline \multirow{12}{*}{ Current Rank/Position } & Nurse 1 & 82 & 54.67 \\
\hline & Nurse 2 & 14 & 9.33 \\
\hline & Nurse 3 & 10 & 6.67 \\
\hline & Nurse 4 & 3 & 2.00 \\
\hline & Nurse 5 & 6 & 4.00 \\
\hline & Nurse 6 & 5 & 3.33 \\
\hline & Nurse 7 & 3 & 2.00 \\
\hline & Supervisor & 7 & 4.67 \\
\hline & Manager & 0 & 0.00 \\
\hline & Head Nurse & 8 & 5.33 \\
\hline & Multiple Positions & 12 & 8.00 \\
\hline & TOTAL & 150 & 100.00 \\
\hline
\end{tabular}


Table 2. Correlation results between NPVS-R and profile of the participants

\begin{tabular}{|c|c|c|c|}
\hline Profile & & Result & Analysis \\
\hline Gender & $\begin{array}{l}\text { Correlation Coefficient } \\
\text { Sig. } 2 \text { tailed } \\
\mathrm{N}\end{array}$ & $\begin{array}{l}-9.6 \% \\
0.24 \\
150\end{array}$ & $\begin{array}{l}\text { There is negligible negative relationship } \\
\text { between gender and value systems. }\end{array}$ \\
\hline Age & $\begin{array}{l}\text { Correlation Coefficient } \\
\text { Sig. } 2 \text { tailed } \\
\mathrm{N}\end{array}$ & $\begin{array}{l}1.4 \% \\
0.86 \\
150\end{array}$ & $\begin{array}{l}\text { There is negligible positive relationship } \\
\text { between age and value systems. }\end{array}$ \\
\hline Religion & $\begin{array}{l}\text { Correlation Coefficient } \\
\text { Sig. } 2 \text { tailed } \\
\mathrm{N}\end{array}$ & $\begin{array}{l}13.1 \% \\
0.11 \\
150\end{array}$ & $\begin{array}{l}\text { There is negligible positive relationship } \\
\text { between religion and value systems. }\end{array}$ \\
\hline Ethnicity & $\begin{array}{l}\text { Correlation Coefficient } \\
\text { Sig. } 2 \text { tailed } \\
\mathrm{N}\end{array}$ & $\begin{array}{l}-31.3 \% \\
0.00 \\
150\end{array}$ & $\begin{array}{l}\text { There is slight negative relationship } \\
\text { between ethnicity and value systems. }\end{array}$ \\
\hline Educational Attainment & $\begin{array}{l}\text { Correlation Coefficient } \\
\text { Sig. } 2 \text { tailed } \\
\mathrm{N}\end{array}$ & $\begin{array}{l}10.6 \% \\
0.19 \\
150\end{array}$ & $\begin{array}{l}\text { There is negligible positive relationship } \\
\text { between educational attainment and } \\
\text { value systems. }\end{array}$ \\
\hline Years of Practice & $\begin{array}{l}\text { Correlation Coefficient } \\
\text { Sig. } 2 \text { tailed } \\
\mathrm{N}\end{array}$ & $\begin{array}{l}14.7 \% \\
0.07 \\
150\end{array}$ & $\begin{array}{l}\text { There is negligible negative relationship } \\
\text { between years of practice and value } \\
\text { systems. }\end{array}$ \\
\hline Work Assignment & $\begin{array}{l}\text { Correlation Coefficient } \\
\text { Sig. } 2 \text { tailed } \\
\mathrm{N}\end{array}$ & $\begin{array}{l}-13.5 \% \\
0.10 \\
150\end{array}$ & $\begin{array}{l}\text { There is negligible negative relationship } \\
\text { between work assignment and value } \\
\text { systems. }\end{array}$ \\
\hline Rank/Position & $\begin{array}{l}\text { Correlation Coefficient } \\
\text { Sig. } 2 \text { tailed } \\
\mathrm{N}\end{array}$ & $\begin{array}{l}1.9 \% \\
0.81 \\
150\end{array}$ & $\begin{array}{l}\text { There is negligible positive relationship } \\
\text { between current rank/position and value } \\
\text { systems. }\end{array}$ \\
\hline
\end{tabular}

Note. Correlation is significant at .05 level (2 tailed); Correlation is significant at .01 level (2 tailed).

In an article titled Have a Personal Value System, ${ }^{[24]}$ indicated that a personal value system "is a set of principles or ideals that drive and/or guide your behavior". Hereford also maintained that a personal value system gives people structure and purpose by helping them to determine what is meaningful and important; i.e., it helps them to express what they stand for. ${ }^{[25]}$

To relate this description of personal values to the results of this study, we can say that a person's professional values and personal values are directly correlated with, and proportional to, each other. ${ }^{[26]}$ Because nurses' personal values are influenced by their childhood experiences regardless of their physical environments, as well as by other factors in their past experiences, those experiences are a significant component of nurses' value systems. ${ }^{[26]}$

This study showed that values are innate elements of human existence that might have environmental influences, but they are still subject to the everyday appraisals that we make regarding what is and what is not important. ${ }^{[27]}$ Because values are innate and flexible, they might change over time depending upon the everyday events that affect one's thought processes and behavior. ${ }^{[27]}$

According to Brown (2001), the values that are pertinent to a profession are those that allow professionals to practice the value system of their chosen field so that they can become instruments of service to the public. These services should benefit society by providing solutions to the needs of the people. $^{[28]}$

The nursing profession reflected in the practice of nurses in Saudi Arabia and anywhere else in the world is devoted to alleviating human suffering and caring for the healthy and sick individuals. Nurses become immersed in their communities and workplaces to be able to understand the needs of the people. ${ }^{[6,23]}$ Therefore, the role of ethics in the profession is to serve as a springboard where nurses base their practice with proven theories while at the same time a tool that guides their practice. ${ }^{[29]}$ Nurses at all times, must adhere to the principles of right and justice as provided for by the Nurses' Code of Ethics especially when faced with a clinical situation that presents a moral conflict. ${ }^{[30]}$

\section{ACKNOWLEDGeMENTS}

This study would not have been possible without the help and assistance of the following persons and organizations:

- the Hail City government hospitals where the data were collected - namely, Hail General Hospital, King Khalid Hospital, and the Maternity and Children's 
Hospital - and gratitude is expressed to their Nursing Department chiefs, their Nursing Continuing Education Department staff, the nursing staff of their wards and units, and their administration staff;

- the teaching and non-teaching staff and students of the College of Nursing of the University of Hail;

- the University Ethics Committee and the University of Hail academic community;
- the statistician, Mr Ramse Osano;

- the editors at a professional editing service; and

- all who in one way or another made this study possible.

\section{CONFlicts OF InTEREST Disclosure}

The authors of this study declare that there is no conflict of interest to any person, party and organization.

\section{REFERENCES}

[1] Nursing stands out as a profession. Nursing. 2006; 36(7): 33 https://doi.org/10.1097/00152193-200607000-00031

[2] Karimi H, Masoudi Alavi N. Florence Nightingale: The Mother of Nursing. Nursing and Midwifery Studies. 2015; 4(2) PMid:26339672 https ://doi .org/10.17795/nms journal294 75

[3] BBC - Primary History - Famous People - Florence Nightingale". Bbc.co.uk. 2017.

[4] Florence Nightingale Facts Summary Information. British Heritage Travel. 2017

[5] Miracle V. National Nurses Week and the Nightingale Pledge. Dimensions of Critical Care Nursing. 2009; 28(3): 145-146. PMid:19387283 https://doi.org/10.1097/DCC.0b013e3181 9 aef $4 \mathrm{e}$

[6] Alkelya M, Haleem R. Investigating Safety-Appraoch in Saudi Arabia Ministry of Health Hospitals. Value in Health. 2013; 16(7): A471A472. https://doi.org/10.1016/j.jval.2013.08.861

[7] Carvalho S, Reeves M, Orford J. Relating your values, morals and ethics to nursing practice. Independent Nurse. 2012; 2012(2).

[8] Hessler K. The Agrarian Vision: Sustainability and Environmental Ethics by Paul B. Thompson. Great Plains Research. 2014; 24(2): 205-205. https://doi .org/10.1353/gpr. 2014.0025

[9] Barazzetti G, Radaelli S, Sala R. Autonomy, Responsibility and the Italian Code of Deontology for Nurses. Nursing Ethics. 2007; 14(1): 83-98. PMid:17334173 https ://doi.org/10.1177/0969 733007069695

[10] Ekendahl K. Personal Value - By Toni Rønnow-Rasmussen. Theoria. 2012; 78(3): 268-272. https ://doi .org/10.1111/j.1755-256 $7.2012 .01135 . \mathrm{x}$

[11] Withryol S, Tyrrell D, Lowden L. Development of incentive values in childhood. 1 st ed

[12] Weis D, Schank M. Development and Psychometric Evaluation of the Nurses Professional Values Scale-Revised. Journal of Nursing Measurement. 2009; 17(3): 221-231. PMid:20069950 https : //doi.org/10.1891/1061-3749.17.3.221

[13] Lin Y, Wang L. A Chinese version of the revised nurses professional values scale: Reliability and validity assessment. Nurse Education Today. 2010; 30(6): 492-498. PMid:19932928 https: //doi.org/10.1016/j.nedt.2009.10.016

[14] Liu M. The Effect of Personal Values on Individuals' Ethical Behavioural Intentions: Evidence from Professional Auditors in People's Republic of China. SSRN Electronic Journal.

[15] Hanks R. Development and testing of an instrument to measure protective nursing advocacy. Nursing Ethics. 2010; 17(2): 255-267. PMid:20185449 https ://doi .org/10.1177/09697330093520 70

[16] Team M, Team M. Kingdom of Saudi Arabia - Ministry of Health Portal [Internet]. Moh.gov.sa. 2017 [cited 17 March 2017]. Available from: http://www.moh.gov.sa/en/Pages/Default.aspx
[17] Kondo M, Nagata H. Nurses' Involvement in Patients' Dying and Death. OMEGA - Journal of Death and Dying. 2015; 70(3): 278-300. PMid:26036056 https : //doi.org/10.1177/00302228155689 59

[18] Vatano lu-Lutz E, Coban M, Izgi M. Are All Deaths the Same for Physicians and Nurses?: Stereotype Questions Physicians and Nurses Utilize to Characterize a Person Who Has Died. OMEGA - Journal of Death and Dying. 2014; 68(4): 367-382. https ://doi .org/10 .2190/OM.68.4.e

[19] Guide to the code of ethics for nurses: interpretation and application Choice Reviews Online. 2008; 46(04): 46-2117-46-2117.

[20] Thompson C, Yang H. Nurses' Decisions, Irreducible Uncertainty and Maximizing Nurses' Contribution to Patient Safety. Healthcare Quarterly. 2009; 12(sp): e178-e185.

[21] Bell L. Code of Ethics for Nurses With Interpretive Statements. Critical Care Nurse. 2015; 35(4): 84-84. https ://doi.org/10.4037/ ccn2015639

[22] Esterhuizen P, Kooyman A. Empowering moral decision making in nurses. Nurse Education Today. 2001; 21(8): 640-647. PMid:11884177 https://doi.org/10.1054/nedt.2001.0647

[23] Almalki M, FitzGerald G, Clark M. The nursing profession in Saudi Arabia: an overview. International Nursing Review. 2011; 58(3): 304 311. PMid:21848775 https://doi.org/10.1111/j.1466-765 $7.2011 .00890 . \mathrm{x}$

[24] Have a Personal Value System [Internet]. Essentiallifeskills.net. 2017 [cited 17 March 2017]. Available from: http://www. essentiall ifeskills.net/personalvaluesystem.html

[25] Irving J, Snider J. Preserving professional values. Journal of Professional Nursing. 2002; 18(1): 5. PMid:11859485 https ://doi .or g/10.1053/jpnu. 2002.30893

[26] Mazhindu D, Griffiths L, Pook C, et al. The nurse match instrument: Exploring professional nursing identity and professional nursing values for future nurse recruitment. Nurse Education in Practice. 2016; 18: 36-45. PMid:27235564 https ://doi.org/10.1016/j.nepr .2016 .03 .006

[27] Basurto Hoyuelos S, Fraile C, Weis D, et al. Nursing professional values: Validation of a scale in a Spanish context. Nurse Education Today. 2010; 30(2): 107-112. PMid:19560234 https ://doi .org/ 10.1016/j.nedt. 2009.05.010

[28] Brown C. Moral Agency and International Society. Ethics \& International Affairs. 2001; 15(02): 87-98. https://doi.org/10.1111/ j.1747-7093.2001.tb00360.x

[29] Brannelly T. Decolonising research practices with the ethics of care. Nursing Ethics. 2016; 23(1): 4-6. PMid:26850458 https: //doi.org/10.1177/0969733015624297

[30] Jamieson S. Building Economic Value for Professional Nurses at the Gateway to the Health Care System. Creative Nursing. 2015; 21(2): 85-91. PMid:26094371 https ://doi .org/10.1891/1078-4535. 21.2 .85 